tolerance is often limited by locomotor rather than cardiovascular disability. Not many want the slightly increased walking time on the treadmill that a dual chamber system offers. ${ }^{1}$

Another clinical issue is that some patients remain in sinus rhythm with intact atrioventricular conduction and need their pacemakers only on very rare occasions when their own conduction falters: they hardly need a dual chamber system. A further drawback to the recommendations is that they are based on data that may be politely described as observational, rather than on the results of prospective randomised trials in defined groups of patients.

In 1992 , one quarter of the 10000 or so pacemakers that were implanted in Britain were dual chamber. The use of such systems varied from $5 \%$ to $75 \%$ in those centres implanting at least 50 units a year. ${ }^{12}$ This remarkable variation cannot be solely due to referral patterns, although some centres specialise in conditions such as the vasovagal syndromes, for which dual chamber pacing is thought to be essential. Clearly the guidelines are being tempered by local circumstances to a remarkable degree.

Guidelines drawn up by experts offer a counsel of perfection that may be inappropriate for day to day practice. Most cardiac centres will be implanting dual chamber systems into patients who are judged to need atrial activity on clinical grounds-that is, those with symptoms on effort and those with heart failure who are not otherwise incapacitated. Directors of public health in purchasing authorities should examine local practices with curiosity and await the results of the various trials of single versus dual chamber pacing that are now underway.

M C PETCH

Papworth Hospital,

Papworth Everard,

Cambridge CB3 8RE

1 Kruse I, Arnman K, Conradson T, Ryden LA. A comparison of the acute and long-term haemodynamic effects of ventricular inhibited and atrial synchronous ventricular inhibited pacing. Circulation 1981;65:846-55.

2 Hesselson AB, Pasonnet V, Bernstein AD, Bonavita GJ. Deleterious effects of long-term singlechamber ventricular pacing in patients with sick sinus syndrome: the hidden benefits of dualchamber ventricular pacing in patients with sick sin.

S chamber pacing. F Am Coll Cardiol 1992;197:1542-9.

4 Travill CM, Sutton M. Pacemaker syndrome: an iatrogenic condition. Br Heart f 1992;68:163-6.

5 Gross JN, Moser S, Benedek ZM, Andrews C, Furman S. DDD pacing mode survival in patients Gross JN, Moser S, Benedek ZM, Andrews C, Furman S. DDD pacin
with a dual-chamber pacemaker. $f$ Am Coll Cardiol 1992;19:1536-41.

with a dual-chamber pacemaker. $f$ Am Coll Cardiol 1992;19:1536-41.
6 Clarke M, Sutton R, Ward D, Camm AH, Rickards A, Ingram A, et al. Recommendations for pacemaker prescription for symptomatic bradycardia. Br Heart 9 1991;66:185-91.

7 ACC/AHA Task Force. Guidelines for implantation of cardiac pacemakers and antiarthythmi devices. I Am Coll Cantiol 1991;18:1-13.

8 De Belder MA, Linker NJ, Jones S, Camm AH, Ward DE. Cost implications of the British pacing and electrophysiology group's recommendations for pacing. BMF 1992;305:861-5.

Ray SG, Girrith MJ, Jamieson S, Bexton RS, Gold RG. Impact of the recommendations of the British Pacing and Electrophysioloog Group on pacemaker prescription and on the immediate costs of pacing in the Northern Region. Br Hean $f$ 1992;68:531-4.

10 Channon KM, Cripps RR, Ormerod O. Recommendations for pacing. BMF 1992;305:1431.

11 Nathan AW, Davies DW. Is VVI pacing outmoded? Br Heart I 1992;67:285-8.

12 British Pacing and Electrophysiology Group. BPEG Data Bulletin 1993; March.

\title{
Doctors and markets
}

\section{Private medicine is a long way from being a perfect market}

Markets when they work perfectly are much the most efficient way to distribute resources. In the widget market beloved of microeconomists the right numbers of the right quality are produced at the optimum price. In contrast, in the planned Soviet style economy many goods are not available at all, some are grossly oversupplied, most are of poor quality, and many are overpriced: resources are used very inefficiently. It is the astonishing efficiency of the perfect market-beautifully analysed by Adam Smith over 200 years ago-that causes so many people to be so fervent about markets and to want them introduced into health care, prisons, and every other sector.

Unfortunately, few if any markets are perfect. The conditions of the perfect market are that buyers and sellers are too small to move the market price by themselves; that sellers have free entry to, and exit from, the market; and that buyers have perfect information about the seller's goods. These conditions are rarely met, and one potent reason why they are not is that sellers will do everything they can to fix a price higher than a perfect market would dictate. Adam Smith wrote in the Wealth of Nations: "People of the same trade seldom meet together, even for merriment and diversion, but the conversation ends in a conspiracy against the public, or in some contrivance to raise prices." One legitimate role of government is to try to ensure that prices are not fixed and that markets operate as near perfectly as possible. This is where antitrust legislation begins, and that is why the Monopolies and Mergers Commission is currently investigating private medical services.

It began its inquiry last September because it believed that the BMA's guidelines on consultant fees, which were first introduced in 1989, might be restricting competition. The commission has now decided that a "complex monopoly" does exist, but it has not decided what remedy to apply. Last week, however, it wrote to all interested parties (including all NHS consultants), sharing the data it has collected and asking for reactions to its work so far and for ideas on what remedies might be applied.

Private medical practice in Britain, which in total the commission estimates to be a business of $£ 9215 \mathrm{~m}$ in 1992 , is far from being a perfect market. Firstly, doctors have to mount substantial barriers to enter the market, particularly as private practice is mostly restricted to consultants. The commission notes in passing that the acceptance in Britain of European Community specialist qualifications could have a considerable effect on the supply of consultants. We are left to infer that this may substantially reduce the prices they can charge. Secondly, the buyers in this market have far from perfect information: rarely have they much idea of the quality of the services they are buying, and often they don't even know the price until they have bought. Buyers tend to rely on general practitioners to guide them, and the commission notes that general practitioners "unwittingly present a barrier to competition" because they don't know about new consultants and their prices. The commission recommended in 1989 that consultants should advertise to general practitioners, but the remedies it is now considering to improve information are to require consultants to make their charges known to patients at the earliest possible opportunity and to let all general practitioners in their area know their charges.

But it's the third impediment to a perfect market-the fact that some sellers might together be able to affect the pricethat most concerns the commission at the moment. This is what started it on the inquiry, and it has now gathered data that 9500 consultants (out of 17000 in the NHS, 2200 in the medical schools, and 6000 who are retired but still in private practice) supply $50 \%$ or more of their services at charges within $2 \%$ of those suggested in the BMA's guidelines or in 
the schedules of procedures suggested by the provident societies. The guidelines and schedules were produced in 1989, and data collected by the commission show a wide variation in charges before 1989 and a convergence thereafter. In March 1989, for instance, surgeons' charges for a coronary bypass graft operation varied from $£ 175$ to $£ 4000$, with $£ 1500$ being levied on 11 occasions and $£ 1600$ on nine occasions. In March 1992 surgeons charged $£ 2000$ on 108 occasions, $£ 1950$ on 11 occasions, and $£ 2200$ on 10 occasions. The maximum suggested by the British United Provident Association was $£ 2000 ; 56 \%$ of surgeons charged that price, and $46 \%$ of anaesthetists charged $£ 825$, the maximum price suggested for them.

The case has been made that the guidelines have a strong impact on the price, and the BMA accepts that a complex monopoly exists within the definitions used by the com- mission. The BMA does not accept, however, that this impact is not in the public interest; it believes that patients should be making their choice on grounds of quality rather than cost. For most economists it is an article of faith that impediments to a free market are a bad thing and that the commission should take some action. The remedies it is considering include prohibiting the BMA from publishing its guidelines and prohibiting insurers from reimbursing claims according to a schedule of procedures. Responses must be in by 4 August, and a final report will be produced probably early next year. Whatever happens, private medicine will remain a long way from being a perfect market, although patients will benefit the closer we come to one.

RICHARD SMITH Editor

\section{The new information management and technology strategy of the NHS}

\section{Person centred}

In the NHS, information technology has so far been perceived mainly as a management tool of little clinical relevance. Professional concern that inappropriate computerisation may harm patient care partly explains this, but the main reason is that NHS policies have given much higher priority to investment in systems for management and administration. By contrast, the new information management and technology (IM\&T) strategy for the NHS in England is "person centred," and patients should benefit directly. ${ }^{1}$ As the strategy is realised the information required for management will increasingly come from clinical computer systems. Because it sets clinical objectives for information technology in the NHS the strategy is to be welcomed.

The new strategy is described in more than 40 separate publications, although no single clear statement of it appears. The handbook for the specialists in information management and technology provides most details. ${ }^{2}$ The strategy's goal is "better health for the nation" achieved by "supporting care and communication through IM\&T." Five principles form the basis of the strategy: information should be person based; systems should be integrated; management information should be derived from operational clinical systems; data should be secure and confidential; and data should be shared across the NHS. To help achieve the strategy there will be facilitating projects (including the integrated clinical work station project), the development of an infrastructure for IM\&T . (including administrative registers and NHS wide networking), central mechanisms for approval of contracts for IM\&T worth more than $f 1 \mathrm{~m}$, and a programme of training. Development of the coding and classification systems (Read codes) will continue through the clinical terms thesaurus. A new format, all digit NHS number will be introduced by 1995-a daunting and expensive task.

The strategy's success will be judged on how useful the new systems are found by health care professionals, particularly doctors and nurses: Mumford has argued that such users will use systems only if they help them achieve professional and personal goals. ${ }^{3}$ The design and evaluation of systems thus require the active participation of practising clinicians. The impact of systems on organisations, clinical process, and clinical outcome needs scientific evaluation. The imposition of systems designed remote from busy clinical environments is likely to be an expensive failure. We now need to build up substantial experience with clinical systems and this will take time.

Computers have many applications in medical records departments, laboratories, pharmacies, and nursing, radiology, and general practice. In addition, they facilitate interdepartmental communication. These aspects seem well covered by the new strategy. But clinicians also need systems for bibliographic retrieval, clinical research, medical education, and the assessment of health care technology and to help in making clinical decisions: this broader vision ${ }^{4}$ is missing. Similarly, links to research and development in clinical medicine and information technology that should be part of such a strategy are missing.

Will industry respond with the products, particularly clinical systems, that such a strategy needs? There is a danger that it is waiting for government money to be put into pilot systems. Industry itself should help define the new market and take a lead in innovative clinical products, with the collaboration of clinicians and researchers.

In all this it is important to acknowledge the world beyond the NHS. If medical data need communicating inside the NHS then they will also need communicating outside it, and the NHS does not need to reinvent standards that are emerging at a European and international level for information technology in health care. Similarly, the results of clinically oriented research and development in the European Community's programme on Advanced Information in Medicine could be usefully exploited.

Clinical Operational Research Unit,

M S LEANING Principal research fellow

University College London

London WC1E 6BT

1 Information Management Group, National Health Service Management Executive, Department of Health. Getting better with information: IMETT strategy overview. London: NHSME, 1992.

2 Information Management Group, National Health Service Management Executive, Department of Health. Getting better with information: handbook for IMET specialists. London: NHSME, 1992.

3 Mumford E. Need for relevance in management information systems: what the NHS can learn from industry. $B M f$ 1992;302:1587-90.

4 Shortliffe EH, Perrault LE, Fagan LM, Wiederhold G, eds. Medical informatics. Computer applications in health care. Reading, Massachusetts: Addison-Wesley, 1990. 